Auster, $\mathrm{n}^{\circ}$ 22, e040, 2017. ISSN 2346-8890

Universidad Nacional de La Plata.

Facultad de Humanidades y Ciencias de la Educación

Centro de Estudios Latinos

\title{
Troya y Roma en algunas Odas de Horacio: traducciones endecasílabas
}

Nota sobre la traducción

El metro elegido para la traducción es el endecasílabo, un metro que tiene amplia tradición en la poesía en español. En el caso de la poesía clásica, en donde la rima no existe, puede decirse que es completamente adecuado, ya que es el tipo de verso que más ha prescindido de ella, aquel en el que se ha producido la mayor cantidad de composiciones no rimadas (salvo, por supuesto, el verso no medido).

La utilización de un metro castellano de fuerte tradición en la historia de la literatura implica el haber descartado cualquier intento de imitar los metros originales, ya que la tradición de la poesía castellana no rimada no ofrece alternativas válidas, es decir, combinaciones métricas con las que el lector pueda estar familiarizado, formas estróficas a las que su oído esté acostumbrado por haber sido ya utilizadas por los poetas que escribieron en nuestra lengua.

En relación con esto, hay que mencionar que la elección de un único tipo de verso para la traducción de todas las odas de Horacio (proyecto en el que se insertan las odas seleccionadas aquí) traiciona, en cierto modo, la intención original del autor de presentar una gran variedad de metros. Esta decisión, que se origina en las limitaciones métricas del castellano en comparación con la lírica clásica, fue tomada teniendo presente el modelo de los Versos Libres de José Martí, un poemario fundamental y fundacional en cuanto al valor del endecasílabo y su flexibilidad para adaptarse a los más variados asuntos y tonos. Horacio, por otro lado, así como Martí, es un autor que se caracteriza por introducir el

Cita sugerida: Kytzler, B. (1978) Horaz, Oden und Epoden (Emilio Rollié, trad.). Auster, (22), e040. Recuperado de: http://doi.org/10.24215/23468890e40 
compromiso político entre otros temas de índole más lírica (dicho esto en la acepción moderna de la palabra) como un aspecto natural en las preocupaciones del poeta.

La traducción en verso, finalmente, no implica ningún tipo especial de licencia ni hace forzosa, de ninguna manera, la infidelidad al original: lo mismo que una traducción en prosa, lo más difícil es lograr un producto aceptable para el lector.

Emilio Rollié

Universidad Nacional de La Plata somasharman@yahoo.com.ar 
I, $8^{1}$

Lydia, dic, per omnis

te deos oro, Sybarin cur properes amando

perdere, cur apricum

oderit campum patiens pulveris atque solis,

cur neque militaris

inter aequalis equitet, Gallica nec lupatis

temperet ora frenis?

cur timet flavum Tiberim tangere? cur olivum

sanguine viperino

cautius vitat neque iam livida gestat armis

bracchia, saepe disco,

saepe trans finem iaculo nobilis expedito?

quid latet, ut marinae

filium dicunt Thetidis sub lacrimosa Troiae

funera, ne virilis

cultus in caedem et Lycias proriperet catervas?

1 Los textos latinos proceden de Kytzler, B., Horaz, Oden und Epoden, Stuttgart 1978 


\section{Traducción}

Di, Lidia, por los dioses inmortales te suplico, por qué con tus amores en arruinar a Síbaris insistes.

Pues ¿por qué abandonó el soleado Campo de Marte el que aguantaba sol y polvo? ¿Por qué entre compañeros de milicia no cabalga y de Galia su caballo con el dentado freno no dirige? ¿Por qué en el claro Tíber le da miedo remojarse? ¿Y por qué con más cautela evita que la sangre de serpiente el aceite de oliva, ni los brazos amoratados luce por las armas el que era muchas veces victorioso de disco en lanzamiento o jabalina la marca traspasando? ¿A qué se esconde, como dicen que el hijo había hecho de Tetis, la del mar, anteriormente de Troya a la caída deplorable para evitar así que sus viriles ropajes al encuentro de la muerte o de licias falanges lo empujaran? 
I, 10

Mercuri, facunde nepos Atlantis, qui feros cultus hominum recentum voce formasti catus et decorae more palaestrae, te canam, magni Iovis et deorum nuntium curvaeque lyrae parentem, callidum quidquid placuit iocoso condere furto.

te, boves olim nisi reddidisses per dolum amotas, puerum minaci voce dum terret, viduus pharetra risit Apollo.

quin et Atridas duce te superbos Ilio dives Priamus relicto Thessalosque ignis et iniqua Troiae castra fefellit.

tu pias laetis animas reponis sedibus virgaque levem coerces aurea turbam, superis deorum gratus et imis. 


\section{Traducción}

Oh, Mercurio, locuaz nieto de Atlante, que las fieras costumbres de los hombres con la palabra, a poco de creados, ablandaste, sagaz, y con el uso de la noble palestra, mensajero de Jove omnipotente y de los dioses, a ti te cantaré, que de la lira curvada eres el padre y un experto en ocultar hurtando jovialmente las cosas a tu antojo. De su aljaba desposeído, Apolo, en otro tiempo, con voz amenazante cuando niño a la vez te asustaba y sonreía, en tanto que las vacas devolvieras robadas con engaños. Y su guía siendo tú, ¿qué decir cuando de Troya salía el rico Príamo burlando a los recios atridas y el inicuo campamento y las tésalas hogueras que a Ilión ponían cerco? A las regiones venturosas tú llevas a las almas piadosas nuevamente y con el áureo cayado las legiones incorpóreas conduces, a los dioses superiores agradable y también a los de abajo. 


\section{I, 12}

Quem virum aut heroa lyra vel acri tibia sumis celebrare, Clio? quem deum? cuius recinet iocosa nomen imago

aut in umbrosis Heliconis oris aut super Pindo gelidove in Haemo? unde vocalem temere insecutae Orphea silvae,

arte materna rapidos morantem fluminum lapsus celerisque ventos, blandum et auritas fidibus cancris ducere quercus.

quid prius dicam solitis parentis laudibus, qui res hominum ac deorum, qui mare ac terras variisque mundum temperat horis?

unde nil maius generatur ipso nec viget quidquam simile aut secundum. proximos illi tamen occupavit Pallas honores

proeliis audax. neque te silebo, 
Liber et saevis inimica virgo

beluis, nec te, metuende certa

Phoebe sagitta.

dicam et Alciden puerosque Ledae, hunc equis, illum superare pugnis

nobilem; quorum simul alba nautis

stella refulsit,

defluit saxis agitatus umor, concidunt venti fugiuntque nubes et minax, quod sic voluere, ponto unda recumbit.

Romulum post hos prius an quietum Pompili regnum memorem an superbos Tarquini fasces dubito an Catonis nobile letum.

Regulum et Scauros animaeque magnae prodigum Paulum superante Poeno gratus insigni referam camena Fabriciumque.

hunc et incomptis Curium capillis utilem bello tulit et Camillum saeva paupertas et avitus apto cum lare fundus. 
Auster, $n^{\circ} 22, \mathrm{e} 040,2017$. ISSN 2346-8890

crescit occulto velut arbor aevo

fama Marcelli: micat inter omnis

Iulium sidus velut inter ignis

luna minores.

gentis humanae pateratque custos,

orte Saturno, tibi cura magni

Caesaris fatis data: tu secundo

Caesare regnes.

ille seu Parthos Latio imminentis

egerit iusto domitos triumpho

sive subiectos Orientis orae

Seras et Indos,

te minor latum reget aequos orbem:

tu gravi curru quaties Olympum,

tu parum castis inimica mittes

fulmina lucis. 


\section{Traducción}

¿De los hombres a cuál o de los héroes celebrar buscas, Clío, con tu lira o con la flauta aguda? ¿De los dioses a cuál celebrarás? ¿El eco alegre qué nombre llevará por las laderas del Helicón umbrío resonando o por el Hemo gélido o el Pindo donde en tropel partieron las florestas tras Orfeo, el de canto melodioso, que con su arte materno demoraba las corrientes veloces de los ríos y los rápidos vientos, con sus cuerdas sonoras encantando las encinas que atentas lo escuchaban? Y primero, ¿qué cosa cantaré sino el encomio acostumbrado al Padre que de dioses y de los hombres guía los asuntos y las tierras y el mar y el curvo cielo con sus tiempos distintos? Mayor nada que sí mismo por él es engendrado ni hay nada semejante o que le siga; aunque honores cercanos a los suyos tiene Palas, audaz en los combates. Y no es posible, Líber, que en silencio te deje, ni a la virgen enemiga 
de las fieras salvajes, ni temido a Febo por sus flechas infalibles. Y a Alcides cantaré junto a los hijos de Leda victoriosos, con caballos el primero y el otro en la pelea, cuyos límpidos astros cuando lucen para el hombre de mar, las blancas olas de las rocas se apartan y los vientos aplácanse y las nubes se dispersan y se aquietan las aguas erizadas, pues así lo desean, en el ponto. Dudo, después, si a Rómulo primero o el apacible reino de Pompilio habré de recordar, o soberbiosas las fasces de Tarquino, o el insigne suicidio de Catón. Y, agradecido, de Régulo y también de los Escauros, y, en dar su noble vida generoso, de Paulo, cuando fue de los fenicios la victoria, hablaré con musa ilustre, y también de Fabricio, al que la cruda pobreza y el solar de sus abuelos y su modesto hogar, junto con Curio de agreste cabellera y con Camilo, los hicieron servir para la guerra. Se acrecienta la fama de Marcelo en el callado tiempo como un árbol y el astro de los Julios resplandece entre todos, así como la luna 
Auster, $n^{\circ} 22, \mathrm{e} 040,2017$. ISSN 2346-8890

alumbra entre menores luminarias.

Oh, protector y padre de la estirpe

de los hombres, saturnio, al que los hados

confiaron la custodia del gran César:

tú reina siendo César el segundo.

Así cuando a los partos que amenazan

el Lacio en justo triunfo sometidos

arrastra, o a los indos o los seras

que habitan los extremos orientales,

reinará sobre el orbe afortunado,

a ti solo inferior por su justicia,

y en pesado carruaje sacudiendo

el Olimpo, a los bosques impiadosos

tú lanzarás tus rayos implacables. 


\section{I, 15}

Pastor cum traheret per freta navibus

Idaeis Helenen perfidus hospitam, ingrato celeris obruit otio ventos ut caneret fera

Nereus fata. «mala ducis avi domum quam multo repetet Graecia milite coniurata tuas rumpere nuptias et regnum Priami vetus.

heu heu, quantus equis, quantus adest viris sudor, quanta moves funera Dardanae genti. iam galeam Pallas et aegida currusque et rabiem parat.

nequiquam Veneris praesidio ferox pectes caesariem grataque feminis inbelli cithara carmina divides, nequiquam thalamo gravis

hastas et calami spicula Cnosii vitabis strepitumque et celerem sequi Aiacem: tamen heu serus adulteros crines pulvere collines.

non Laertiaden, exitium tuae 
Auster, $\mathrm{n}^{\mathrm{o}} 22$, e040, 2017. ISSN 2346-8890

genti, non Pylium Nestora respicis?

urgent inpavidi te Salaminius

Teucer, te Sthenelus sciens

pugnae, sive opus est imperitare equis, non auriga piger. Merionen quoque

nosces. ecce furit te reperire atrox

Tydides melior patre:

quem tu, cervus uti vallis in altera

visum parte lupum graminis inmemor, sublimi fugies mollis anhelitu, non hoc pollicitus tuae.

iracunda diem proferet Ilio

matronisque Phrygum classis Achillei:

post certas hiemes uret Achaicus

ignis Iliacas domos.» 
Traducción

Al pérfido pastor cuando en su barco del Ida se escapaba por los mares con su huésped Helena, así Nereo, deteniendo con calma inoportuna los vientos favorables, su luctuoso destino le anunciaba: "En mala hora conduces a tu patria a la que Grecia unida para ruina de tus nupcias y de Príamo el reino esclarecido reclamará con miles de guerreros. ¡De los caballos, ay, y de los héroes cuánto sudor! ¡Cuán grande es la matanza que a la estirpe de Dárdano acarreas! Ya apresta Palas su égida y su yelmo y su furia guerrera y su carruaje.

En vano peinarás tu cabellera, valeroso de Venus al amparo, ni a mujeres los cantos agradables podrás acompañar con esa lira que no sabe de guerras. Será en vano que intentes en el tálamo las lanzas pesadas evitar y las cretenses saetas afiladas y el estruendo y al veloz Áyax, listo a perseguirte. Y sin embargo, ay, aunque ya tarde, 
tu cabellera adúltera con polvo

ensuciarás. ¿Al hijo de Laertes,

perdición de tu pueblo, no distingues,

ni a Néstor, el de Pilos? Ya te acechan

quienes no temblarán: de Salamina

conocerás a Teucro, y con las armas

a Esténelo probado y, si es preciso

dirigir los caballos, buen auriga,

y también a Merión. Y el de Tideo,

más fuerte que su padre, detrás tuyo

he aquí que va, atroz y enfurecido, aquel del que huirás cobardemente, con resuello agitado, igual a un ciervo que del pasto se olvida al ver un lobo del valle en un rincón (cuando a tu amada le prometías algo diferente).

Para Ilión y las madres de los frigios

demorado será el último día

por la flota colérica de Aquiles;

y al pasar cierto número de inviernos las moradas de Pérgamo incendiadas por el fuego serán de los aquivos". 
II, 4

Ne sit ancillae tibi amor pudori, Xanthia Phoceu: prius insolentem

serva Briseis nive ocolore

movit Achillem,

movit AiacemTelamone natum

forma captivae dominumTecmessae, arsit Atrides medio in triumpho

virgine rapta,

barbarae postquam cecidere turmae

Thessalo victore et ademptus Hector tradidit fessis leviora tolli

Pergama Grais.

nescias an te generum beati

Phyllidis flavae decorent parentes;

regium certe genus et penatis

maeret iniquos.

crede non illam tibi de scelesta

plebe dilectam neque sic fidelem, sic lucro aversam potuis se nasci matre pudenda.

bracchia et voltum teretesque suras 
integer laudo - fuge suspicari -

cuius octavum trepidavit aetas

claudere lustrum.

\section{Traducción}

No te cause pudor por una esclava, Jantia de Fócide, tu amor: pues antes con su níveo color al fiero Aquiles lo enamoró Briseida, esclava suya; a Áyax también, de Telamón el hijo, lo atrapaba Tecmesa, la cautiva, con su belleza; en medio de su triunfo por la virgen robada ardió el Atrida una vez que las bárbaras legiones cayeron, vencedor el de Tesalia, y la pérdida de Héctor a los griegos cansados una Pérgamo más fácil les dio para que fuera destruida. Ignoras si, quizás, como su yerno los padres te honrarán afortunados de Fílide, la rubia; con certeza una estirpe real ella deplora y penates injustos: considera que del impío vulgo la elegida, tan fiel y ajena al lucro, no es posible que de una madre vil haya nacido. Sus piernas modeladas y su rostro 
Auster, no 22 , e040, 2017. ISSN 2346-8890

y sus brazos elogio francamente;

no sospeches de un hombre cuya vida

se apuró a clausurar los ocho lustros. 